\title{
Е.И. Самофалова
}

\section{МЕТОДОЛОГИЯ АНАЛИЗА ОБРАЗОВАТЕЛЬНОЙ МИГРАЦИИ В СОЦИАЛЬНОЙ ФИЛОСОФИИ В ОТЕЧЕСТВЕННОЙ МЫСЛИ}

\begin{abstract}
Описываются основные аспекты методологического анализа феномена образовательной миграции в социильной философии. Раскрываются основнье составляющие феномена, ключевые аспекты онтологического понятийного аппарата и история изучения образовательной миграции в отечественной мысли.

Ключевые слова: сочиальная философия, история изучения образовательной миграции, методология анализа, образовательная миграции, учебная миграция.
\end{abstract}

Миграция населения - это общественный феномен, существующий на всем протяжении развития человеческого общества и социальных институтов. Население, являющееся с точки зрения социальной философии не просто «совокупностью людей, но и специфической системой общественных связей и отношений» [1. С. 102], представляет собой ценностную основу для изучения миграции и ее проблемных зон. Так, общеизвестно, что существование различных точек зрения по тем или иным научным проблемам довольно часто может быть объяснено просто: они возникают из-за того, что для одних и тех же понятий используются разные, а для различных понятий применяются одинаковые термины. В данном случае философскими выкладками могут пользоваться другие науки: социология, демография, культурология и т.д., так как анализ миграционных процессов без участия философского контекста попросту невозможен. Существуют также другие области применения философского анализа миграционных процессов. В частности, различные страны могут руководствоваться различными аксиологическими принципами миграционной политики в контексте обеспечения устойчивого развития [2].

В целом философский аспект миграции состоит в выяснении ее сущностных и ценностных характеристик, динамического и статического опыта, различных личностных трансформаций, и именно специфика философских исследований способна объединить все существующие на данный момент знания о миграции в целостную систему. Таким образом, миграция есть «проявление социальной диалектики, что делает возможным восприятие ее как предмета для исследования в социальной философии» [3. С. 4], а общим предметом ее изучения является ,пространственное“ выражение социального воспроизводства человеческой жизни, интеллекта и культуры» [Там же]. В современной традиции существуют также особенные термины - «человек мигрирующий» и «глобалмиграция» [4], обозначающие проблемно-ориентированный понятийный комплекс во всей его полноте.

Образовательная миграция, в свою очередь, - довольно специфическая область для изучения. С одной стороны, она имеет непосредственное отношение к необходимости социокультурной адаптации в чужой образовательной среде, переосмыслению индивидуального и социального бытия в контек- 
сте нового социального опыта, а также к необходимости действовать и выражать собственные чаяния на другом языке, т.е. фактически создавать себе другую личность или образовывать новые специфические социальные общности - различные варианты национальных общин, гетто, анклавов или чайнатаунов в азиатском варианте. С другой стороны, человек - существо социальное, и поэтому его индивидуальные представления об образовательной реальности могут находиться в когнитивном, социальном и психологического диссонансе с существующим положением вещей. Таким образом, миграционные образовательные процессы обусловлены как множеством объективных факторов (специфические исторические и национальные условия жизни стран, их культурное своеобразие, особенности существования экономики, действия господствующей в обществе политической элиты и т.д.), так и субъективными обстоятельствами, многие из которых носят трудно предсказуемый и противоречивый характер. Можно сказать также, что «... миграционный фактор предполагает указание пути не столько в географических, сколько в эмоциональных ориентациях» [5. С. 6; 6], охватывая, таким образом, как внешнюю, так и внутреннюю компоненту онтологического процесса поиска смысла. При этом лейтмотивом понимания образовательной миграции является ее «имманентная конфликтогенная природа» [3]: между мигрантом и принимающей средой, между мигрантами и принимающим обществом и социальным институтами, психологические личностные конфликты мигрантов и т.п. Также следует разделять понятия «эмигрант» и «иммигрант», являющиеся кардинально противоположными не только по смыслу, но и точки зрения влияния на индивида его социально-психологического статуса [7].

При философском анализе образовательной миграции необходимо учитывать несколько ключевых моментов, которые могут более четко определить ее гносеологический аспект:

- объективно-субъективный характер основного феномена - так, «до начала XX в. миграция зачастую могла быть вызвана или остановлена властными распоряжениями» [2]. Однако в постиндустриальном обществе в связи с большим социоэкономическим ресурсным разрывом между странами миграция обусловлена (за исключением вынужденной) либо индивидуальными стремлениями к материальному благу [8], либо образовательными целями в самом широком смысле слова;

- мотивы миграции - ранее таковыми являлись военные походы, колонизация, работорговля, освоение новых земель. В современном обществе превалируют экономические, политические и образовательные причины;

- формы миграции - традиционное общество было в большей степени оседлым, чем современное, поэтому в первом случае миграция оказывала менышее влияние на социальные процессы, нежели в наше время, когда от интенсивности миграции зависят важные статистические (политические, культурные, экономические, образовательные, демографические, религиозные) показатели региона;

- масштабы миграции - по данным ООН, «с начала XXI в. миграцией охвачено 218 стран, количество людей, живущих вне стран своего рождения или гражданства, оценивается в 258 млн человек, что составляет около $3,4 \%$ от общей численности населения мира, из них более $2 \%$ - беженцы $[6,9]$; 
- мировоззрение исследователя - зачастую в предлагаемых социальнофилософских концепциях содержатся «одномерные», или «линейные», решения конкретных миграционных вопросов вследствие отсутствия единого понимания феномена [10].

Таким образом, социальная философия, изучая предметное содержание феномена, может составить сущностное представление о миграционных процессах и актуализировать ранее не обсуждаемые вопросы. Однако для более глубокого понимания самой природы образовательной миграции и особенно ее интенсификации в настоящее время необходимо также исследовать общие предпосылки миграционных процессов. Если рассматривать эти факторы с точки зрения социальной философии, то все их можно разделить на два типа: онтологические и гносеологические [11].

Гносеологические предпосылки исследования миграционных процессов связаны с раскрытием сути и содержания миграции, изучением образовательной миграции как особого социального института. Изучением миграции традиционно занимаются демография, статистика и экономика, социология предлагает социальные основания для изучения, социальная философия теоретическое обоснование проблемных аспектов. Среди известных исследователей миграции можно назвать Э. Равенстейна, К. Кэрри, У. Изарда (гравитационные модели миграции), С. Стоуферра («модель промежуточных возможностей»), Р. Викермана, М. Гринвуда, И. Лоури, А. Роджерса (регрессионный анализ) и т.П. В российской практике следует упомянуть Т.И. Заславскую, Л.Л. Рыбаковского, Ж.А. Зайончковскую, Г.С. Витковскую, Л.Ч. Курбанову, Е.Е. Письменную, В.И. Мукомеля, Т.Н. Юдину, А.Н. Николенко.

К онтологическим (т.е. имеющим отношение к социальной действительности), в свою очередь, можно отнести следующие предпосылки.

Экономические предпосылки. Современные миграционные процессы обусловлены в первую очередь неравномерным распределением ресурсов и информационных технологий в обществе. Так, по данным ООН, 6 из 7 людей планеты живут в малопригодных для жизни условиях [12]. «Развитие производства, формирование современного рынка, усилившего внутри- и межгосударственный обмен трудовыми ресурсами, оказали... сильнейшее влияние на интенсификацию миграций» [13]. Чем выше уровень постиндустриализации и, соответственно, выше уровень жизни, тем более эта территория привлекательна для мигрантов [2], особенно для мигрантов образовательного толка, из-за возрастающих социокультурных возможностей.

Демографические предпосылки. На данный момент, по мнению большинства исследователей, мир находится в состоянии демографического перехода, который обычно выражается в «стремительном росте популяции и наступающем затем стремительном спаде, после чего численность населения стабилизируется». В развитых странах этот переход уже завершен, в развивающихся странах - продолжается, а «страны третьего мира» только вступают в это состояние [Там же]. В свою очередь, образовательная миграция в мире занимает на данный момент около 15-20\% от общего потока. Это означает, что каждый пятый-шестой человек предпочитает получать образование за рубежом. Демографические диспропорции также способствуют возрастанию миграционных потоков: например, по данным западных источников доля 
женщин-мигрантов по отношению к мужчинам в мировой миграции составляет в среднем $5: 3$ [14].

Социальные предпосылки. В современном обществе большое значение приобретают социально-психологические аспекты взаимодействия людей; высока роль межличностных, межгрупповых и межобщинных связей; также необходимо учитывать реакцию на мигрантов принимающего общества.

Политико-правовые предпосылки. Современные политические процессы способны провоцировать обширные миграционные потоки, в основном вынужденного характера, вследствие войн, конфликтов, террористических актов, различных видов преследования по политическим мотивам или соответствующей политики правительства по отношению к некоренному населению [15]. Вынужденная миграция может заставить государство корректировать собственную нормативно-правовую базу в соответствии с условиями жизни мигрантов (например, в США, где представительства национальных меньшинств добиваются права участвовать в законодательном процессе страны) [16].

Этнокультурные предпосылки. В данном случае следует учитывать национальное самосознание и множественные конфликты на национальной почве, которые являются одной из причин вынужденной миграции, а также некоторые социокультурные аспекты: культурные ценности общества, общую гражданскую лояльность к мигрантам и возникающие в связи с этим проблемы с лояльностью (подробнее см.: [17]).

Экологические предпосылки. Новый фактор, который стремительно набирает силу начиная с середины XX в. Проблемы загрязнения окружающей среды и различных антропогенных воздействий на нее заставляют людей избирать себе другую среду для проживания. Однако, с другой стороны, сами мигранты способны создать чрезмерную нагрузку на окружающую среду вследствие целого ряда социокультурных факторов [18].

В теориях изучения миграции с точки зрения философского анализа нет единого подхода или разработанного категориального аппарата. В отечественной практике к концу XX в. можно проследить несколько подходов к общему изучению миграции; так, насчитывается около сорока определений в зависимости от объекта и метода исследований [1. С. 160]. При этом следует учитывать, что начиная с середины XX в. и вплоть до сегодняшнего времени в силу ряда причин (экономически и политически обоснованных) ученые обращались в основном к изучению трудовой миграции, феномена беженцев или изучению различных видов перемещения населения. Например, с точки зрения Б.С. Хорева, миграция рассматривается в узком смысле как «совокупность безвозвратных межпоселенных передвижений населения» и эквивалентна понятию «переселение» [19. С. 145]. Данного подхода придерживается и В.И. Староверов (рассматривал различные функции миграции: перераспределительную, демографическую и т.д.) [20. С. 22]. В.И. Переведенцев, наоборот, говорил о миграции в широком, философском смысле, смешивая понятия территориальности, социальности и т.п., определяя ее как «совокупность всяких перемещений людей в пространстве», зачастую приравнивая к понятию «мобильность» [21. С.9]. К данной группе определений можно также отнести работы М.В. Курмана (миграция - это любая форма социального движения) [22] и А.У. Хомры (понимает под ми- 
грацией все типы перемещений, начиная от понятия «подвижность» до любого перемещения в пространстве, иногда даже в метафизическом аспекте) [20].

На данный момент в российской научной среде чаще всего употребляется подход Л.Л. Рыбаковского, определившего в 1970-е гг. миграцию как «территориальное перемещение, совершающееся между разными населенными пунктами одной или нескольких административно-территориальных единиц, независимо от продолжительности, регулярности и целевой направленности» [23. С. 7]. Это определение считается в некоторой степени универсальным для отечественной социальной философии, так как учитывает основные черты нескольких подходов. Однако в основном ученые рассматривают и изучают миграцию в зависимости от типа, приводя определения к каждой отдельной ее составляющей.

На современном этапе можно выделить несколько основных теоретических подходов к исследованию миграционных процессов. Например, Н.И. Шекихачева [24] говорит о следующих направлениях для философского анализа:

1. Культурологическая концепция - миграция как процесс взаимодействия между людьми двух разных стран и в рамках пространства, включающего в себя обе стороны. Взаимодействие может осуществляться в рамках вынужденной, трудовой или образовательной миграции.

2. Теория ассимиляции - принцип однолинейности процесса адаптации мигрантов к обществу страны въезда. Данная теория является частью более общей функционалистской парадигмы в социальной философии, применяемой для изучения вопросов иностранных и национальных меньшинств.

3. Этносоциологическое направление - базируется на концепции культуры как коллективного способа адаптации к окружающей природной и социальной среде. На этом уровне учитываются исторические традиции народа, отражающие прежний миграционный опыт. Именно в рамках данного подхода получило развитие понимание не только межгосударственных миграций, но и внутренних перемещений людских потоков.

4. Теория социальных изменений - миграция рассматривается как своеобразная социальная система, процессуальность которой имеет атрибутивный характер.

5. Институциональный подход - миграционная мобильность населения как межинституциональная научно-практическая проблема.

Обратимся далее к собственно феномену образовательной миграции. Как было указано выше, конкретного определения феномена в социальной философии не существует до сих пор. Более того, в социально-философской мысли присутствует несколько различных точек зрения: что именно понимать под образовательной миграцией, отличаются ли образовательная и учебная миграции друг от друга ареалом для изучения, а также какие цели данные типы миграции преследуют. При этом в западной литературе разделения на образовательную и учебную миграцию вообще нет. Направления для исследований в основном характеризуются конкретными целями в зависимости от науки, с одной стороны, и объекта изучения - с другой. Таким образом, феномен образовательной миграции остается одним из самых противоречивых областей знания. Тем не менее неизменной остается социальная направленность в проблематике, а также выяснение психологических особенностей об- 
разовательного мигранта и различных типов взаимосвязей между ним и принимающим сообществом.

Исходя из анализа литературы, объектом исследования образовательной миграции в отечественной социальной философии можно считать «социальное взаимодействие индивидов, вовлеченных в социально-географическое перемещение с целью получения образования», а предметом - «динамику изменений объективных и субъективных аспектов социальных отношений индивидов в рамках прежнего и нового социумов» [25]. Это означает, что образовательная миграция в научной сфере охватывает достаточно специфическую область знаний, подразумевающую под собой различные способы объяснений одного и того же явления.

По существующему делению миграционных процессов в социальной философии феномен образовательной миграции возможно также разделить на несколько стадий: подготовительную, основную и заключительную [Там же]. Также существует деление образовательной миграции по пространственно-временным параметрам, условным и воображаемым границам, степени интенсивности, а также по степени комплементарности «принимающего» и «прибывающего» сообществ. В последнем случае область для изучения значительно расширяется.

Согласно общей социофилософской парадигме образовательной миграции все действия в данной сфере характеризуются принятой в обществе концепцией «трансграничного (транснационального) образования». Под этим термином подразумеваются в широком смысле слова все виды образовательных программ и действий, связанных с образованием, для которых необходимо пересечение границ государств, в узком - «образование, которое осуществляется на территории другой страны» [26. С. 4]. Таким образом, с точки зрения функций трансграничное образование позволяет популяризировать отечественную науку для мирового сообщества, расширить межкультурное сотрудничество между образовательными средами разных стран, а также обеспечить мигранту социокультурный комплекс условий для гармоничного развития личности. С точки зрения теории трансграничное образование позволяет определить онтологические, гносеологические и культурологические аспекты человеческого бытия в единую систему.

В отечественной философской традиции при изучении истории миграционных процессов и трансформации человеческого опыта в этой связи принято выделять следующие этапы:

1) дореволюционный (со второй половины XIX в. до 1917 г.);

2) с 1920-х гг. до начала 1930-х гг.;

3) с 1950-1960-х гг. до 1990-х гг.;

4) с 1990-х гг. по настоящее время [27. С. 56].

Во время первого этапа изучение образовательной миграции практически не велось, однако большое внимание уделялось в целом изучению миграционных процессов и управленческих процессов, с ними связанных. Это было обусловлено активной колонизацией Россией сопредельных территорий (в частности, Кавказа, Центральной Азии), поэтому политика освоения земель была тесно связана с общими миграционными исследованиями, одновременно велись различные статистические и демографические исследования. Основным источником информации по вопросам миграции служили так 
называемые переселенческие пункты, где скапливалась информация о мигрантах. Мнения ученых, занимавшихся данным вопросом ${ }^{1}$, в целом сводились к следующим принципам:

- колонизация - это позитивный опыт на этапах развития человечества, позволяющий развивать сельское хозяйство и наращивать военную мощь страны;

- возможное переселение завоеванных народов должно происходить поэтапно, желательно в близлежащие районы или необжитые места;

- благотворительные меры для стимулирования миграции пагубны, так как это способствует миграции более слабого, экономически незащищенного населения.

В 1905 г. А.А. Кауфман написал работу, связанную с учетом переселений и колонизации новых земель малоземельными крестьянами, объединив, таким образом, основные отечественные изыскания по этому поводу [22]. Касательно образовательной миграции особых научных исследований не проводилось, кроме общего учета количества иностранных студентов.

Второй этап исследования образовательной миграции связан с образованием СССР. Изучение образовательной миграции в стране шло в соответствии с социофилософскими принципами марксизма-ленинизма: значимость образования для каждого человека, необходимость применения учения Маркса-Ленина для образовательного процесса. Например, активно продвигалась мысль В.И. Ленина о том, что образовательный уровень населения свидетельство его социального развития, органическим элементом которого является повышение его подвижности [23. С. 12]. Также образовательный и культурный подъем масс населения является одним из ключевых факторов повышения производительности труда [Там же. С. 40]; при этом личность должна воспринимать повышение собственного уровня образования как необходимую ценность, долг гражданина перед Родиной. Таким образом, общее среднее образование являлось одним из необходимых социальных рычагов управления страной. Понятие образовательной миграции по-прежнему не выделялось отдельной категорией в исследованиях, более того, миграция рассматривалась в основном в контексте исторических наук. Характерной чертой данного этапа также является в основном «обслуживающий», прикладной характер исследований миграционных процессов. Одновременно с практикой шли теоретические споры по поводу определения ключевых понятий: «миграция», «переселение», «факторы миграции» и т.д.

Третий этап изучения связан с окончанием Второй мировой войны, когда в СССР начали приезжать на обучение представители стран Восточной Европы - Польши, Румынии, Югославии, Болгарии. Значительно снизились показатели плановой миграции и возросли показатели индивидуальной. Особое внимание уделялось изучению образовательными мигрантами русского языка. Грамотная политика СССР по привлечению образовательных мигрантов, включающая в себя сложную систему долгосрочных договоров между странами, позволила количественно увеличить число образовательных мигрантов.

\footnotetext{
${ }^{1}$ Например, работы Г.К. Гинка, А.А. Кауфмана, И.А. Гурвича и т.д.
} 
В сфере исследований миграции образовались две основных научных школы - московская и сибирская. Среди ученых, работавших над данным вопросом, можно выделить Л.Л. Рыбаковского, активно исследовавшего миграционные процессы в целом, обобщившего теоретические наработки в данной области. Образовательная миграция не выделялась в отдельную отрасль знания, однако можно определить основные научные разработки:

- социальная функция миграции всецело определяется уровнем экономического развития страны и проводимой ею политикой;

- показатели стабильности миграционных потоков (в том числе образовательной миграции) характеризуют степень стабильности состава населения;

- склонность к образовательной миграции наиболее сильна в молодом возрасте (до 30-35 лет), а затем постепенно снижается;

- исследование факторов миграции невозможно без учета психологических и социальных аспектов жизни индивида;

- вне зависимости от реакции индивида на окружающие его условия, от объективных или субъективных факторов, механизм принятия решения о миграции (в том числе и образовательной) выносится на поведенческий уровень и обусловлен внутренней структурой личности, с одной стороны, и процессами социализации его в родном и принимающем сообществе - с другой. Также имеет значение несоответствие между реальными потребностями индивида и возможностями для их удовлетворения [28. С. 34];

- для процесса принятия решения о миграции не нужно сопоставление реальной ситуации в стране (регионе)-реципиенте с желаемой - в данном случае, скорее, будет работать понятие «идеальной формы». Удовлетворенность образовательного мигранта будет связана с уровнем его «приживаемости» на новом месте, когда миграционный процесс будет завершен. Возможные возникающие противоречия будут, скорее всего, связаны с растущими потребностями личности (вследствие повышения уровня образования) и невозможностью их удовлетворить. Таким образом, речь может идти о своего рода фрустрации: иррациональной неудовлетворенности и желании перемен, при этом объективное положение вещей (экономическая, политическая ситуация, уровень заработной платы) не играет особо важной роли;

- большинство факторов, в соответствии с которыми происходит миграция - экономические; образовательная миграция, помимо процесса получения новых знаний, также имеет под собой устойчивую экономическую основу: стремление в будущем улучшить свое материальное и социальное положение.

Четвертый этап изучения образовательной миграции начался в 90-х гг. прошлого века и продолжается в настоящее время. Именно на данном этапе отечественные ученые обратились к опыту зарубежных коллег, четко разделив виды и особенности миграции между собой, обозначив теоретикометодологические аспекты миграции и факторы, ведущие к миграционному процессу. Образовательная миграция в этом случае начала представлять собой обширное поле для исследований вследствие необходимости привлечения в вузы иностранных студентов по экономическим, политическим и социально-демографическим причинам. Россия потеряла свои лидирующие позиции в мире в качестве страны-реципиента для образовательных мигран- 
тов и до сих пор не смогла полностью восстановить их. В то же время начался активный процесс «утечки мозгов» - т.е. обратной образовательной миграции, когда из страны уезжали молодые и перспективные ученые, не имеющие возможности работать на родине. Феноменальный рост количества университетов (в середине 2000-х гг. примерно в 6 раз по сравнению с 1980-ми) не исправил ситуации, так как уровень образования в них был достаточно низким не только для образовательных мигрантов, но и для отечественных студентов. В 2006 г. в послании президента В.В. Путина впервые прозвучал призыв к инновационным способам развития общества и поддержке национальных образования и науки.

С другой стороны, в научных исследованиях образовательной миграции произошел резкий качественный скачок. Появились попытки выстроить собственную терминологию и методологию исследования в социальной философии, исследовать факторы образовательной миграции и ее место в миграционных процессах в целом. Также образовательная миграция перестала рассматриваться исключительно как территориальное перемещение: теперь дистанционное обучение при помощи Интернета или Скайпа также попадает в данную категорию.

Таким образом, на сегодняшний день в сфере философско-социологической мысли возможно выделить несколько направлений для изучения данного феномена.

Статистико-демографические аспекты - различные статистические данные необходимы для проведения социологических исследований, отслеживания результатов различных образовательных реформ, связанных с миграцией, а также статистического учета мигрантов. В основном в России этим успешно занимается Центр социального прогнозирования (в частности, Ф.Э Шереги и А.Л. Арефьев), публикующий ежегодные отчеты об образовательной миграции в России, а также различные миграционные службы. Также к данной области изучения можно отнести прикладные исследования различных национальных групп мигрантов, которые проводятся регулярно и в достаточном количестве.

Философско-теоретические проблемы - исследования различных подходов к изучению феномена, роли миграции в жизни индивида или принимающего региона; разработка терминологии и различных методик для исследования; исследования в области социологии управления. Среди ученых, занимающихся данной проблематикой, можно выделить Л.Л. Рыбаковского, Ж.А. Зайончковскую, Е.Е. Письменную, В.И. Мукомеля.

Политический аспект - в данном случае изучается влияние миграционной политики России на иностранных студентов, а также различные последствия образовательных реформ и различные правовые аспекты образовательной политики по отношению к мигрантам. Данным вопросом занимаются, в частности, Е.Н. Алексеева, О.Д. Выхованец, С.В. Дементьева, М.В. Дюжакова, Д.Н. Митин.

Психолого-педагогическая адаптация образовательных мигрантов на новом месте обучения и к новым условиям жизни (России в целом, региону, конкретному населенному пункту) исследуется достаточно широко вследствие актуальности темы и больших методологических возможностей. Среди исследователей, занимающихся этим вопросом, следует упомянуть 
С.В. Дементьеву, С.В. Бондаренко, Е.В. Афонину, Л.И. Бутенко, Д.В. Василенко, М.А. Иванову, Е.А. Нагайцеву, Л. Тьерри, Д.А. Соколова, А.С. Ильину, В.П. Филиппову и т.д. В основном исследования тесно взаимосвязаны с психологией и основываются на том, что современная высшая школа, признавая в качестве основополагающего принципа принцип гуманизации образования, выступает как система условий, обеспечивающих развитие личности во всех ее проявлениях. Поэтому влияние вуза на процесс социокультурной адаптации студентов-мигрантов позволяет провести этот процесс с наименьшими временными и психологическими затратами. С другой стороны, изучаются различные психологические проблемы, возникающие у студентов в процессе обучения: от чувства одиночества до суицидального поведения.

Таким образом, учитывая все вышесказанное, для социальной философии образовательная миграция является важным с научной точки зрения феноменом, изучение которого позволит глубже понять состояние нашего общества и социальные процессы, происходящие в нем. Одновременно с этим «усложняющаяся реальность и отсутствие комплексного междисциплинарного подхода в миграционной политике способствуют неуправляемости современных миграций» [28]. Поэтому в сложившихся условиях предметом анализа социальной философии должна стать образовательная миграция как основа для социальной диалектики, как социальный институт, который в эпоху глобализации является одной из доминант общественного развития.

\section{Литература}

1. Юдина Т.Н. О социологическом анализе миграционных процессов // Социс. 2002. № 10. C. $102-108$.

2. Петров В.Н. Социальные функции миграций населения в российском обществе: некоторые проблемы теоретико-методологического анализа региональных различий // Ломоносовские чтения. 2002. T. 2. URL: http://lib.socio.msu.ru/l/library? $=\mathrm{d}-000-00---0$ lomon--00-0-00prompt-10---4------0-11--1-ru-50---20-help---00031-001-1-0windowsZz-1251-00\&cl=CL1\&d=HASH $24 \mathrm{e} 2 \mathrm{~b} 873166 \mathrm{c} 0400 \mathrm{e} 23 \mathrm{bdb} .15 \& \mathrm{gc}=1$ (дата обращения: 01.06.2019).

3. Дрокин M.C. Социально-философский анализ феномена миграции : дис. ... канд. филос. наук. M., 2011. 121 c. URL: http://www.dslib.net/soc-filosofia/socialno-filosofskij-analiz-fenomenamigracii.html (дата обращения: 06.05.2019).

4. Преображенская Н.М. Миграция в условиях глобализации: социально-философские аспекты : дис. .... канд. филос. наук. М., 2011. 190 с.

5. Метелев И.С. Феномен миграции (методология анализа и жизненный смысл). Омск : Изд. Омск. ин-та (филиала) РГТЭУ, 2010. 115 с.

6. Lüdemann E., Schwerdt G. Migration background and educational tracking. Springer-Verlag 2012. 27 p. URL: http://download.springer.com/static/pdf/318/art\%253A10. 1007\%252Fs00148-012-0414z.pdf?auth66=1386478054_ed44037922f476943bab2e3685a4eccf\&ext=.pdf(accessed: 17.05.2019).

7. Дыжин C.E. Социально-философский анализ проблемы национального самосознания мигранта // Исторические, философские, политические и юридические науки, культурология и искусствоведение. Вопросы теории и практики. 2017. № 12, ч. 2. С. 82-85.

8. Смирнов С.A. Антропология перехода. URL: http://www.antropolog.ru/doc/persons/smirnov/smirnov2 (дата обращения: 15.05.2019).

9. Centre for Multicultural youth Issues. Information sheet № 11 - Refugee and CLD Young people: definition. Carlton, Victoria, 2005.

10. Переведенцев В.И. Методы изучения миграции населения. М. : Наука, 1975. 231 с.

11. Glick Schiller N., Basch L., Szanton Blanc C. Transnationalism: a new analytic framework for understanding migration // Toward a Transnational Perspective on Migration / N. Glick Schiller, C. Basch (eds.). New York : New York Academy of Sciences, 1992. P. 1-24.

12. World Migration Report 2017. International Organization for Migration. P. 5.

13. Выхованеи O. Миграция. Развитие. Характеристики. Проблемы. URL: http://antropotok. archipelag.ru/text/a302.htm (дата обращения: 13.03.2019). 
14. Varshney D., Lata S. Female migration, Education and Occupational Development: a Geospatial Analysis of Asian countries // Environment and Urbanization Asia. 2014. Vol. 5 (185). 33 p.

15. Belot M., Ederveen S. Cultural barriers in migration between OESD countries // J. Popul Econ. 2012. № 25. P. 1077-1105.

16. Patten E. Statistical portrait of the foreign-born population in the United States. Washington, DC : Pew Hispanic Centre, 2012.

17. Философия и миграция. URL: https://www.deutschland.de/ru/topic/politika/filosofia-imigracia (дата обращения: 30.05.2019).

18. Piper N. Migration and social development / United Nations Research Institute for Social Development, Social Policy and Development Programme. Paper № 39, April 2009. 34 p.

19. Алисов Н.В., Хорев Б.С. Экономическая и социальная география мира (общий обзор) : учебник. М. : Гардарики, 2003. 704 с.

20. Староверов В.И. Социально-демографические проблемы деревни. М. : Наука, 1975.

21. Курман М.В. Актуальные вопросы демографии. М. : Статистика, 1976. 220 с.

22. Кауфман А.А. Переселения и колонизация. СПб., 1905. 443 с. (Библиотека «Общественной пользы»).

23. Рыбаковский Л.Л. Миграция населения. Три стадии миграционного процесса (очерки теории и методов исследования). М. : Наука, 2001. 114 с.

24. Шекихачева Н.И. Теоретико-методологические основы изучения вынужденной миграции как социального процесса // Материалы XXXIV научно-технической конференции по результатам работы профессорско-преподавательского состава, аспирантов и студентов за 2004 год. Ставрополь, 2005 // Северо-Кавказский государственный технический университет. URL: http://www.ncstu.ru (дата обращения: 15.05.2019).

25. Самофалова Е.И. Образовательная миграция: проблемное поле и основные характеристики. URL: http://scipeople.ru/publication/69692/ (дата обращения: 30.04.2019).

26. Ечевская О.Г. Академическая мобильность и образовательные миграции в Сибири: проблемы и перспективы // Экономика. Вопросы школьного экономического образования. 2012. № 3. C. 3-10.

27. Хомра А.У. Миграция населения: вопросы теории, методики исследования. Киев : Наукова думка, 1979. $148 \mathrm{c}$.

28. Шереги Ф.Э., Дмитриев М.Н., Арефьев А.Л. Россия на мировом рынке образовательных услуг. URL: http://www.demoscope.ru/weekly/2003/097/analit03.php (дата обращения: 10.05.2019).

Elena I. Samofalova, Tomsk State University (Tomsk, Russian Federation).

E-mail: elena.sm83@gmail.com

Vestnik Tomskogo gosudarstvennogo universiteta. Filosofiya. Sotsiologiya. Politologiya - Tomsk State University Journal of Philosophy, Sociology and Political Science. 2019. 50. pp. 75-87.

DOI: $10.17223 / 1998863 \mathrm{X} / 50 / 8$

METHODOLOGICAL ANALYSIS OF EDUCATIONAL MIGRATION IN SOCIAL PHILOSOPHY IN THE DOMESTIC THOUGHT

Keywords: social philosophy; educational migration; methodological analysis.

The article deals with the main aspects of the methodological analysis of the educational migration phenomenon in the social philosophy. The main components of the phenomenon, the key aspects of the ontological conceptual apparatus and the history of educational migration studies in the domestic thought are revealed. Educational migration is a rather specific research field. Nowadays, there is no special definition of the phenomenon in social philosophy. On the one hand, educational migration is directly correlated with the need of a sociocultural adaptation in a foreign educational environment, of the rethinking of individual and social being in the context of a new social experience, as well as with the need to act and express one's own aspirations in another language, in fact, to create another personality or form new specific social communities, such as various versions of national communities, ghettos, enclaves, or Chinatowns. On the other hand, a person is a social creature; therefore, his/her individual ideas about an educational reality can be in a cognitive, social and psychological dissonance with the existing state of affairs. According to the general socio-philosophical paradigm of educational migration, all actions in this area are characterized by the concept of "cross-border (transnational) education" adopted in society. A philosophical analysis of educational migration needs to take into account several key points that can more clearly define its epistemological aspect. Among them are the objective-subjective nature of the main phenomenon, the motives and forms of migration, 
its historical terms, as well as the philosophical view of the researcher. For a deeper understanding of the nature of educational migration and especially its intensification, it is also necessary to explain the general prerequisites of migration processes, which can be divided into two types: ontological and epistemological. There are several basic theoretical approaches to the study of migration processes, e.g., the culturological concept, the theory of assimilation, the ethno-sociological theory, the theory of social change and the institutional approach. Due to its functions, educational migration allows popularizing national science for the world community, expanding intercultural cooperation between educational environments of different countries, as well as providing a migrant with a socio-cultural complex of conditions for the harmonious development of a personality. From the conceptual point of view, the concept of cross-border education allows setting the ontological, epistemological and culturological aspects of human existence into a single system.

\section{References}

1. Yudina, T.N. (2002) O sotsiologicheskom analize migratsionnykh protsessov [On sociological analysis of migration processes]. Sotsis - Sociological Studies. 10. pp. 102-108.

2. Petrov, V.N. (2002) Sotsial'nye funktsii migratsiy naseleniya v rossiyskom obshchestve: nekotorye problemy teoretiko-metodologicheskogo analiza regional'nykh razlichiy [Social functions of the population migration in the Russian society: some problems of theoretical and methodological analysis of the regional varieties]. Lomonosovskie chteniya. 2. Proc. of the Conference. [Online] Available from: http://lib.socio.msu.ru/l/library? $=\mathrm{d}-000-00---0 l o m o n--00-0-0-0 p r o m p t-10---4------0-11--1-r u-$ 50---20-help---00031-001-1-0windowsZz-1251-

$00 \& \mathrm{cl}=\mathrm{CL} 1 \& \mathrm{~d}=\mathrm{HASH} 24 \mathrm{e} 2 \mathrm{~b} 873166 \mathrm{c} 0400 \mathrm{e} 23 \mathrm{bdb} .15 \& \mathrm{gc}=1$ (Accessed: 1st June 2019).

3. Drokin, M.S. (2011) Sotsial'no-filosofskiy analiz fenomena migratsii [Socio-philosophical analysis of migration]. Philosophy Cand. Diss. Moscow. [Online] Available from: http://www.dslib.net/soc-filosofia/socialno-filosofskij-analiz-fenomena-migracii.html (Accessed: 5th May 2019).

4. Preobrazhenskaya, N.M. (2011) Migratsiya v usloviyakh globalizatsii: sotsial'no-filosofskie aspekty [Migration under globalization: socio-philosophical aspects]. Philosophy Cand. Diss. Moscow.

5. Metelev, I.S. (2010) Fenomen migratsii (metodologiya analiza i zhiznennyy smysl) [The phenomenon of migration (methodology of analysis and life meaning)]. Omsk: Omsk Institute (Branch) of Russian State University of Trade and Economics.

6. Lüdemann, E. \& Schwerdt, G. (2012) Migration background and educational tracking. SpringerVerlag. [Online] Available from: http://download.springer.com/static/pdf/318/art\%253A10.1007\% 252Fs00148-012-0414-z.pdf?auth66=1386478054_ed44037922f476943bab2e3685a4eccf\&ext=.pdf (Accessed: 17th May 2019).

7. Dyzhin, S.E.(2017) Social and philosophical analysis of the problem of migrant's national self-consciousness. Istoricheskiye, filosofskiye, politicheskiye i yuridicheskiye nauki, kul'turologiya $i$ iskusstvovedeniye. Voprosy teorii i praktiki - Historical, Philosophical, Political and Law Sciences, Culturology and Study of Art. Issues of Theory and Practice. 12(86-2). pp. 82-85. (In Russian).

8. Smirnov, S.A. (n.d.) Antropologiya perekhoda [Anthropology of Transition]. [Online] Available from: http://www.antropolog.ru/doc/persons/smirnov/smirnov2 (Accessed: 15th May 2019).

9. Centre for Multicultural Youth Issues. (2005) Information sheet № 11 - Refugee and CLD Young people: definition. Carlton, Victoria.

10. Perevedentsev, V.I. (1975) Metody izucheniya migratsii naseleniya [Methods for Studying the Population Migration]. Moscow: Nauka.

11. Glick Schiller, N., Basch, L. \& Szanton Blanc, C. (1992) Transnationalism: a new analytic framework for understanding migration. In: Glick Schiller, N. \& Basch, C. (eds) Toward a Transnational Perspective on Migration. New York : New York Academy of Sciences. pp. 1-24.

12. International Organization for Migration. (2018) World Migration Report 2017. pp. 5.

13. Vykhovanets, O. (n.d.) Migratsiya. Razvitie. Kharakteristiki. Problemy [Migration. Development. Properties. Problems]. [Online] Available from: http://antropotok.archipelag.ru/text/a302.htm (Accessed: 13th March 2019).

14. Varshney, D. \& Lata, S. (2014) Female migration, Education and Occupational Development: a Geo-spatial Analysis of Asian countries. Environment and Urbanization Asia. 5(185). DOI: 10.1177/0975425314521549

15. Belot, M. \& Ederveen, S. (2012) Cultural barriers in migration between OESD countries. Journal of Popul Econ. 25. pp. 1077-1105. DOI: 10.1007/s00148-011-0356-x

16. Patten, E. (2012) Statistical portrait of the foreign-born population in the United States. Washington, DC: Pew Hispanic Centre. 
17. Germany. (n.d.) Filosofiya i migratsiya [Philosophy and Migration]. [Online] Available from: https://www.deutschland.de/ru/topic/politika/filosofia-i-migracia (Accessed: 30th May 2019).

18. Piper, N. (2009) Migration and social development. United Nations Research Institute for Social Development, Social Policy and Development Programme Paper. 39.

19. Alisov, N.V. \& Khorev, B.S. (2003) Ekonomicheskaya i sotsial'naya geografiya mira (obshchiy obzor) [Economic and social world geography]. Moscow: Gardariki.

20. Staroverov, V.I. (1975) Sotsial'no-demograficheskie problemy derevni [Socio-demographic problems of the village]. Moscow: Nauka.

21. Kurman, M.V. (1976) Aktual'nye voprosy demografii [Topical Questions of Demography]. Moscow: Statistika.

22. Kaufman, A.A. (1905) Pereseleniya i kolonizatsiya [Migration and Colonization]. St. Petersburg: Biblioteka Obshchestvennoy pol'zy.

23. Rybakovsky, L.L. (2001) Migratsiya naseleniya. Tri stadii migratsionnogo protsessa (Ocherki teorii i metodov issledovaniya) [Population migration. Three stages of migration (Essays of theory and research methods)]. Moscow: Nauka.

24. Shekikhacheva, N.I. (2005) [Theoretical and methodological foundations of the study of forced migration as a social process]. Materialy XXXIV nauchno-tekhnicheskoy konferentsii po rezul'tatam raboty professorsko-prepodavatel'skogo sostava, aspirantov i studentov za 2004 god [Proceedings of the 34th scientific and technical conference on the results of the work of the faculty, graduate students and students for 2004]. Stavropol. [Online] Available from: http://www.ncstu.ru (Accessed: 15th May 2019).

25. Samofalova, E.I. (n.d.) Obrazovatel'naya migratsiya: problemnoe pole i osnovnye kharakteristiki [Educational migration: the problem field and basic characteristics]. [Online] Available from: http://scipeople.ru/publication/69692/ (Accessed: 30th April 2019).

26. Echevskaya, O.G. (2012) Akademicheskaya mobil'nost' i obrazovatel'nye migratsii v Sibiri: problemy i perspektivy [Academic mobility and educational migration in Siberia: problems and prospects]. Ekonomika. Voprosy shkol'nogo ekonomicheskogo obrazovaniya. 3. pp. 3-10.

27. Khomra, A.U. (1979) Migratsiya naseleniya: voprosy teorii, metodiki issledovaniya [Population migration: problems of theory and methods of research]. Kyiv: Navuk. Dumka.

28. Sheregi, F.E., Dmitriev, M.N. \& Arefiev, A.L. (2003) Rossiya na mirovom rynke obrazovatel'nykh uslug [Russia on the world market of educational services]. [Online] Available from: http://www.demoscope.ru/weekly/2003/097/analit03.php (Accessed: 10th May 2019). 